\title{
New approaches in the management of insomnia: weighing the advantages of prolonged-release melatonin and synthetic melatoninergic agonists
}

This article was published in the following Dove Press journal:

Neuropsychiatric Disease and Treatment

9 June 2009

Number of times this article has been viewed

\author{
Rüdiger Hardeland \\ Johann Friedrich Blumenbach Institute \\ of Zoology and Anthropology, \\ University of Göttingen, Germany
}

\begin{abstract}
Hypnotic effects of melatonin and melatoninergic drugs are mediated via $\mathrm{MT}_{1}$ and $\mathrm{MT}_{2}$ receptors, especially those in the circadian pacemaker, the suprachiasmatic nucleus, which acts on the hypothalamic sleep switch. Therefore, they differ fundamentally from GABAergic hypnotics. Melatoninergic agonists primarily favor sleep initiation and reset the circadian clock to phases allowing persistent sleep, as required in circadian rhythm sleep disorders. A major obstacle for the use of melatonin to support sleep maintenance in primary insomnia results from its short half-life in the circulation. Solutions to this problem have been sought by developing prolonged-release formulations of the natural hormone, or melatoninergic drugs of longer halflife, such as ramelteon, tasimelteon and agomelatine. With all these drugs, improvements of sleep are statistically demonstrable, but remain limited, especially in primary chronic insomnia, so that GABAergic drugs may be indicated. Melatoninergic agonists do not cause next-day hangover and withdrawal effects, or dependence. They do not induce behavioral changes, as sometimes observed with z-drugs. Despite otherwise good tolerability, the use of melatoninergic drugs in children, adolescents, and during pregnancy has been a matter of concern, and should be avoided in autoimmune diseases and Parkinsonism. Problems and limits of melatoninergic hypnotics are compared.
\end{abstract}

Keywords: agomelatine, hypnotics, melatonin, prolonged-release, ramelteon, tasimelteon

\section{Introduction}

Insomnia is a highly common disorder, which is experienced by almost everybody, at least at advanced age, and becomes chronic in about $10 \%$ of the population. Because of the transient nature of its milder forms, its importance is frequently underrated. On the other hand, the treatment of severe sleep disturbances, such as primary chronic insomnia, is challenging and frequently complicated by comorbid symptoms. ${ }^{1-3}$ The etiology of insomnia is obviously divergent. It is sometimes related to psychiatric or neurologic diseases that may develop already in younger or middle-aged subjects. Moreover, it may be acquired as a consequence of neurodegenerative disorders including Alzheimer's disease, ${ }^{4}$ especially when the circadian pacemaker, the suprachiasmatic nucleus ( $\mathrm{SCN})$, or its downstream connections are affected. ${ }^{5-7}$ Circadian rhythm sleep disorders (CRSDs) may be present or develop independently of neurodegeneration. In particular, familial advanced sleep phase syndrome (FASPS) and delayed sleep phase syndrome (DSPS) are characterized by exceptionally short or long spontaneous circadian period lengths. Other circadian disorders are related to weak coupling with external time cues, eg, in some blind subjects. Typically, CRSDs cause transient or periodically occurring forms of insomnia.$^{8-10}$ For the circadian system, a possible
Correspondence: Rüdiger Hardeland Johann-Friedrich-Blumenbach-Institut für Zoologie und Anthropologie, Universität Göttingen, Berliner Str. 28, D-37073

Göttingen, Germany

Tel +4955I 3954l4

$\mathrm{Fax}+49551395438$

Email rhardel@gwdg.de 
mode of intervention is that of favoring synchronization with the environment. Apart from bright light in the morning, ie, enhancement of Zeitgeber strength to reinforce coupling with light onset, melatonin may be administered in the evening to make use of the re-synchronizing, chronobiotic as well as sleep onset-promoting properties of this molecular mediator of the darkness signal. In fact, melatonin was shown to be effective in the treatment of various forms of CRSDs. ${ }^{1-14}$

While the use of the chronobiotic melatonin in CRSD is plausible for mechanistic reasons, its application in other types of insomnia does not warrant immediate success, but has been worthy of exploration. In neurobiological terms, the actions of melatonin on sleep are largely of a chronobiological nature. High densities of the membrane-bound, G protein-coupled melatonin receptors $\mathrm{MT}_{1}$ and $\mathrm{MT}_{2}$ are found in the $\mathrm{SCN}$, where the pineal hormone acts in a dual way, by resetting the clock - mainly via $\mathrm{MT}_{2}$ - and by suppressing neuronal firing - mainly via $\mathrm{MT}_{1} \cdot{ }^{15-19}$ Leaving aside some complexities of the signaling mechanisms, ${ }^{19}$ the $\mathrm{MT}_{1}$-mediated effects of melatonin on the SCN favor sleep initiation especially, but perhaps not exclusively via the hypothalamic sleep switch. This structure exhibits on-off responses ${ }^{20-22}$ and suppresses, under the influence of melatonin, the wake-related neuronal downstream pathways ("off") and promotes the sleep-related ones ("on"). ${ }^{23,24}$ However, sleep is a complex phenomenon that involves numerous brain regions. Melatonin receptors have been detected in various parts of the brain, but receptor densities are considerably lower than in the SCN. ${ }^{25-28}$ The thalamus has been assumed to be also involved in soporific actions of melatonin. ${ }^{29,30}$ Melatonin receptors are expressed in this region, and spindle formation is promoted by the indoleamine. ${ }^{29-31}$ Spindles are characteristics of non-REM (rapid eye movement) sleep, and are involved in the transition from stage 2 sleep to deeper sleep stages. However, a major problem for judging the relative importance compared to the primary SCN-mediated effects results from the complexity of the neuronal connections. Apart from the thalamocortical interplay, which is necessary for spindle formation, the thalamus also influences the SCN. Inputs to the SCN are known from various other brain areas, too, especially from the intergeniculate leaflet, ${ }^{30}$ which is connected to many parts of the brain and also receives a photic input. ${ }^{32}$ At the present state of our knowledge, the problem remains as to what extent the thalamus and other brain areas may assist the SCN by transmitting melatonin-dependent responses, and whether SCN-independent actions of melatonin are sufficient for sleep promotion. In individuals with severe SCN dysfunction and melatonin deficiency, exogenous melatonin was found to be insufficient for substantially mitigating sleep difficulties. ${ }^{33}$ However, SCN destruction, which causes sleep fragmentation and losses of circadian rhythmicity, still allows spindle formation. ${ }^{30}$ Another source of complexity results from the necessary integration of primarily chonobiotic and homeostatic components of sleep regulation. The homeostatic mechanism also comprises a circadian component, ${ }^{24,34,35}$ and the existence of a separate homeostatic oscillator has been proposed. ${ }^{36}$ The extent of melatonin's influences on homeostatic sleep may deserve further attention. At least, melatonin has been reported to be useful under conditions of an insufficient homeostatic drive to sleep. ${ }^{37}$ Despite the highly complex interplay of brain areas during sleep, and the existence of presumably multiple inputs from melatonin, primary and secondary actions have to be distinguished. The phase-resetting effects are relatively well understood and a participation of the SCN in sleep initiation cannot be denied. Melatoninergic actions in other brain areas and their contribution to sleep require further elucidation. With regard to the high receptor density and the knowledge of SCN-mediated actions, the influence of melatonin on the circadian pacemaker will be the focus of our considerations.

Melatonin differs in its mode of action from other hypnotics such as benzodiazepines and z-drugs (zolpidem, zaleplon, zopiclone, eszopiclone), which lead to a more generalized central nervous depression via $\mathrm{GABA}_{\mathrm{A}}$ receptors. Melatonin is capable of indirectly influencing GABAergic mechanisms involved in sleep-related routes downstream of the SCN. ${ }^{20-22}$ Indirect GABAergic effects in other brain areas may, possibly, play an additional role. Only at strongly elevated pharmacological concentrations can melatonin exert more generalized sedative or even narcotic effects, which are, however, mediated by other mechanisms, such as antiexcitatory suppression of calcium signaling and inhibition of neuronal NO synthase. ${ }^{38}$ Moreover, melatonin contrasts with benzodiazepines and z-drugs with regard to sleep architecture, ie, the relative duration of sleep stages (stages 1-4), which differ in sleep depth and undergo an ultradian REM/nonREM cycle of about 90 minutes duration. While sleep architecture can be considerably changed by GABAergic drugs, the ultradian cycle is usually poorly influenced by melatonin, perhaps because this periodicity is generated by another, the pontine sleep switch, ${ }^{39,40}$ which does not seem to be a major target of melatonin. However, melatonin was reported to increase REM sleep duration in a subgroup of patients with reduced REM sleep. ${ }^{41}$ In this context, the SCN is, again, not independent of inputs from other brain areas, since certain SCN neurons were found to fire more rapidly during REM than 
nonREM phases ${ }^{24}$ notwithstanding the primarily suppressive $\mathrm{MT}_{1}$ signaling. Therefore, these changes within the REM/ nonREM cycle do not reflect direct melatoninergic actions, although they are relevant to sleep and may be indirectly influenced by the hormone.

In CRSDs, a melatonin surge of relatively short duration can be sufficient for resetting the circadian clock, at least when applied in a suitable phase of the phase-response curve. However, in primary chronic insomnia, the major obstacle for the use of melatonin as a clinically efficient hypnotic drug was assumed to result from its extremely short half-life in the circulation, which is mostly in the range of 20 to 30 minutes, sometimes even less, but maximally about 45 min..$^{20-22,42}$ Although a short-acting compound may promote sleep initiation, it can improve sleep maintenance only marginally. Theoretically, this problem has two solutions. One is a prolonged-release formulation of melatonin, the other the development of long-acting melatoninergic agonists. Both possibilities have been studied and given rise to the production of approved or investigative drugs. Their relative advantages will be discussed and, where appropriate, also compared to the nonmelatoninergic, primarily GABAergic, hypnotics that are currently in use.

\section{Signaling and pharmacology of melatoninergic agonists}

At therapeutic doses, the hypnotic actions of melatonin and synthetic melatoninergic drugs are mediated by the membrane receptors $\mathrm{MT}_{1}$ and $\mathrm{MT}_{2}$, as outlined above. In addition to the first-discovered agonist-dependent decreases in cAMP, a more complex system of signaling routes has been identified that contributes to the cellular effects. ${ }^{19}$ These include phospholipase $\mathrm{C}$ activation, in the case of $\mathrm{MT}_{2}$, and control of inward rectifier $\mathrm{K}^{+}$(Kir) channels, with secondary effects on voltage-gated $\mathrm{Ca}^{2+}$ channels, by $\mathrm{MT}_{1} \cdot{ }^{19}$ These last actions may be particularly relevant to the suppression of neuronal firing and, thereby, contribute to sleep induction via the hypothalamic sleep switch.

While phase shifting and neuronal suppression in the SCN represent a basis of hypnotic actions of all melatoninergic drugs, sleep research literature frequently ignores the fact that the membrane-bound melatonin receptors are not restricted to the SCN. Even though receptor density may be lower in other target tissues or cells, any melatoninergic agonist has to be expected to exert additional effects via these receptors, eg, in the immune system, the gastrointestinal tract, the vasculature, other central nervous structures and various hormonal subsystems. ${ }^{18,19,43-45}$ Therefore, by contrast with other hypnotics, any of the melatoninergic drugs is, for fundamental reasons, not only a soporific agent, but also a regulator of other physiological functions. These additional effects, which are frequently disregarded, may not always be beneficial, especially in patients suffering from autoimmune diseases or Parkinson's disease (see following sections).

While signaling and distribution of $\mathrm{MT}_{1}$ and $\mathrm{MT}_{2}$ receptors discriminate melatoninergic agonists from GABAergic hypnotics, melatonin also differs from its synthetic analogs in the spectrum of binding sites. Several other melatonin-binding sites beyond the $\mathrm{G}$ protein-coupled $\mathrm{MT}_{1}$ and $\mathrm{MT}_{2}$ receptors have been identified, ${ }^{19,44,45}$ which either display negligible affinity to the synthetic analogs, or have not yet been tested. These additional binding sites include quinone reductase 2 (formerly believed to represent a third membrane receptor), nuclear receptors belonging to the retinoic acid receptor superfamily, in particular, ROR $\alpha 1, \mathrm{ROR} \alpha 2, \mathrm{RZR} \alpha$ and RZR $\beta$, calciumbinding proteins such as calmodulin (presumably requiring pharmacological levels because of low affinity), calreticulin, nuclear calreticulin analogs, and two mitochondrial binding sites, one of which is located at the amphipathic ramp of complex 1 and displays high affinity to the indoleamine. ${ }^{19,21,43-45}$ The majority of synthetic agonists has not been tested for these binding sites, with the exception of ramelteon, which has a low affinity to quinone reductase $2,{ }^{46}$ and does not seem to act via calmodulin. ${ }^{21}$

In addition to its direct actions, melatonin is metabolized to various bioactive compounds, including indolic (eg, 5-methoxytryptamine, $\mathrm{N}$-acetylserotonin) and kynuric [ $N^{1}$-acetyl- $N^{2}$-formyl-5-methoxykynuramine (AFMK) and $N^{1}$-acetyl-5-methoxykynuramine (AMK)] substances and their derivatives (Figure 1). ${ }^{43-45}$ For reasons of chemical dissimilarity, no homologs of these melatonin metabolites can be formed from nonindolic drugs. Among the hypnotics tested, only the investigative drug $\beta$-methyl-6-chloromelatonin might lead to some homologous derivatives (Figure 1). ${ }^{47}$ In conclusion, the full spectrum of actions known from melatonin, which also comprises various beneficial effects, ${ }^{38,44}$ cannot be expected to be found with nonindolic hypnotics. On the other hand, those drugs showing selectivity towards $\mathrm{MT}_{1}$ and $\mathrm{MT}_{2}$ receptors also exert effects beyond sleep promotion.

The various melatoninergic agonists tested for soporific effects exhibit substantial differences in receptor affinity, half-life, metabolism, and contribution of metabolites to sleep promotion. Melatonin itself has different affinities to human $\mathrm{MT}_{1}$ and $\mathrm{MT}_{2}$ receptors $\left(\mathrm{K}_{\mathrm{i}}=80.7\right.$ and $383 \mathrm{pM}$, respectively). ${ }^{21,47}$ Its physiological half-life in the circulation is, as mentioned, usually less than half an hour, mainly 


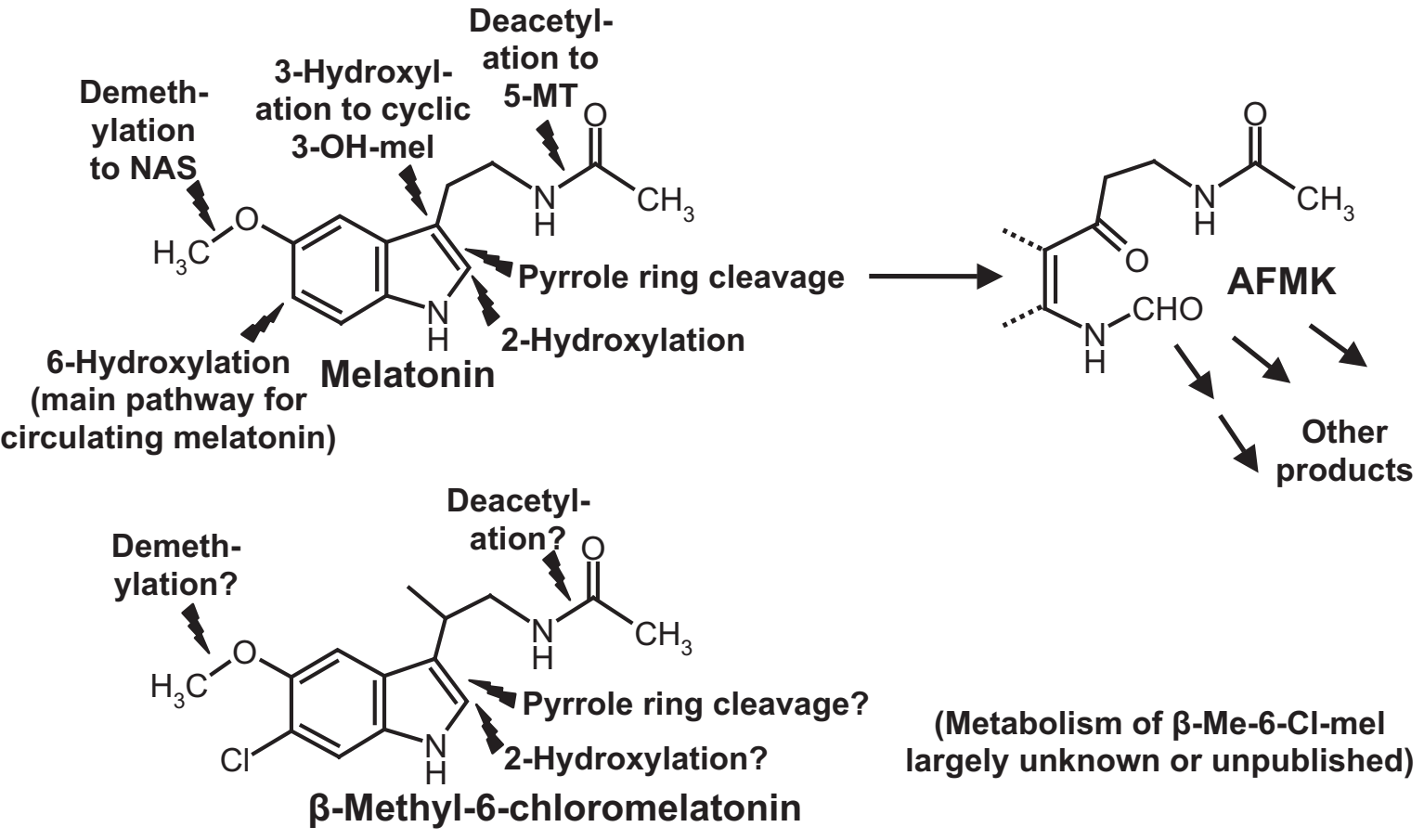
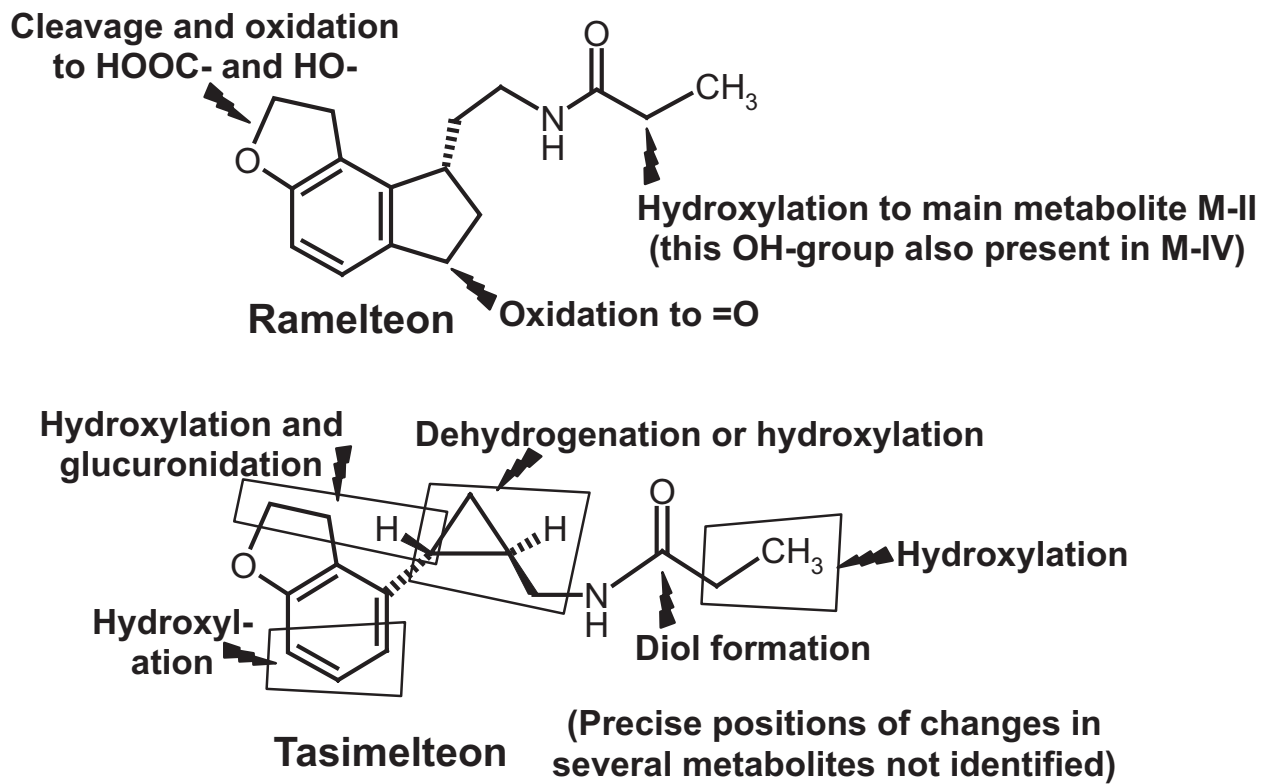

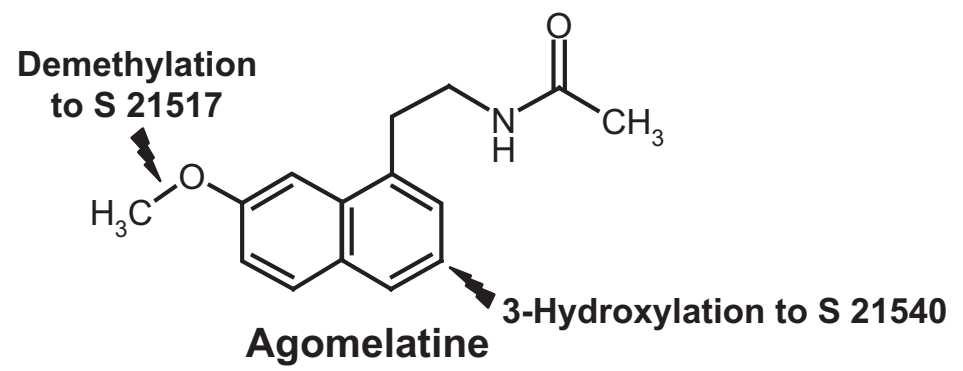

Figure I Chemical structures and main metabolic routes of melatonin and synthetic melatoninergic hypnotics. Flashes $=$ sites of metabolic reactions.

Abbreviations: AFMK, $N^{\prime}$-acetyl- $N^{2}$-formyl-5-methoxykynuramine; Me, methyl; mel, melatonin; 5-MT, 5-methoxytryptamine; NAS, $N$-acetylserotonin. For other details see current text. 
because of rapid hepatic 6-hydroxylation by cytochrome $\mathrm{P}_{450}$ monooxygenase subforms, in particular, CYP1A2, but also CYP1A1 and CYP1B1. ${ }^{48,49}$ 6-Hydroxymelatonin is conjugated and excreted. In other tissues, especially the brain, melatonin can be metabolized differently. ${ }^{43}$ No soporific effects are known from any of melatonin's natural metabolites, except for 5-methoxytryptophol. ${ }^{50}$ The sleep-related effects of this compound are presumably without physiological significance. However, the indolic, partially serotoninergic ${ }^{43}$ metabolites, 5-methoxytryptamine and $\mathrm{N}$-acetylserotonin, should be tested in more detail for possible interferences with sleep or wakefulness.

All these considerations are relevant to immediate and prolonged-release melatonin as well, with a main difference in bioavailability. Among the various formulations used in different studies, the brand Circadin ${ }^{\circledR}$ will be particularly considered, because of its approval by the European Medicines Agency (EMEA). Circadin ${ }^{\circledR}$ has been developed by Neurim, Israel and UK (marketing authorization holder) and is now also provided by Lundbeck and by Nycomed. In April 2007, it received marketing authorization by EMEA for the treatment of insomnia in patients aged 55 years and over. It was licensed for the combination of improvement of sleep quality and next-day feeling. The pharmacokinetics of Circadin ${ }^{\circledR}$, which requires more detailed future investigation, has been tested in 8 healthy male subjects receiving 1,2, 4 or $8 \mathrm{mg}$ of the prolonged-release formulation at $10 \mathrm{AM}$, either in conjunction with fasting or with a standard meal. ${ }^{51}$ The unusual time of administration was obviously chosen to better demonstrate the efficacy of the slow-release formulation and to avoid interference with the endogenous melatonin peak. Normally, melatonin is given shortly (30 minutes) before bedtime, according to the time profile of the natural hormone, which exhibits, at least, in healthy nonelderly subjects a pronounced nocturnal peak. However, the pharmacokinetics of melatonin may differ between daytime and nighttime hours, according to data from rats which received continuous infusions of melatonin. ${ }^{52}$ This possibility should be considered in humans, too. Under the conditions tested in humans, $2 \mathrm{mg}$ led to a shift of $\mathrm{T}_{\text {max }}$ from about $4 \mathrm{PM}$ to about 11.30 $\mathrm{AM}$ (without meal) or $12.30 \mathrm{PM}$ (with meal). ${ }^{51}$ These values should not be overinterpreted, since peaks resulting from the drug should not be compared with the physiological nocturnal maximum. $\mathrm{C}_{\max }$ values, as presented, have to be regarded as preliminary, since they showed considerable variation among the relatively few volunteers [without drug: range 30 to $126 \mathrm{pg} / \mathrm{mL}$ (median $51 \mathrm{pg} / \mathrm{mL}$ ); drug and fasting: range 180 to $855 \mathrm{pg} / \mathrm{mL}$ (median $393 \mathrm{pg} / \mathrm{mL}$ ); drug with meal: 205 to $1020 \mathrm{pg} / \mathrm{mL}$ (median: $390 \mathrm{pg} / \mathrm{mL}$ )]. In the $24 \mathrm{~h}$-AUC values, a considerable interindividual variation was, again, observed [basal: range 150 to 1017 $\mathrm{pg} \times \mathrm{h} / \mathrm{mg}$ (median $375 \mathrm{pg} \times \mathrm{h} / \mathrm{mg}$ ); drug and fasting: range 823 to $4478 \mathrm{pg} \times \mathrm{h} / \mathrm{mg}$ (median $2257 \mathrm{pg} \times \mathrm{h} / \mathrm{mg}$ ); drug with meal: range 618 to $5252 \mathrm{pg} \times \mathrm{h} / \mathrm{mg}$ (median 2010 $\mathrm{pg} \times \mathrm{h} / \mathrm{mg}$ )]. These data merely show that this melatonin formulation causes increases in blood levels, what had to be expected, but the improvements in duration of elevated bioavailability, compared to immediate-release melatonin, are not sufficiently evident from published data. $\mathrm{T}_{\max }$ and $\mathrm{C}_{\max }$ values are not suitable for judging the advantage of prolonged release. Elimination time has been inferred to be the same ( $\mathrm{t}_{1 / 2}$ about 40 to 50 minutes) as with conventional melatonin preparations, ${ }^{51}$ although this may be dose-dependent. In another study on healthy volunteers of both genders, aged 55 to 69 years, the effect of food on AUC after $2 \mathrm{mg}$ Circadin ${ }^{\circledR}$ revealed only minor changes. ${ }^{51}$ A major difficulty in interpreting the pharmacokinetic data results from the very high interindividual variability. This is not uncommon with melatonin in general and is usually explained by differences in the rapid first-path hepatic metabolism of the hormone. Whether this is really so, especially when authors are claiming a more than $80 \%$ elimination via 6-hydroxylation and conjugation, ${ }^{51}$ may be debated. Additional variation may result from the gut, which is both a source and sink of melatonin, ${ }^{53-56}$ allows enterohepatic cycling of this compound, ${ }^{55-58}$ contains by two orders of magnitude more melatonin than the pineal gland, ${ }^{54}$ and can release melatonin in terms of a postprandial response..$^{54,55,59}$ Gastrointestinal release of melatonin in response to tryptophan was associated with profound sleep promoting effects. ${ }^{53}$ Because of these complexities and difficulties concerning pharmacokinetics, the advantages of prolonged-release melatonin should be judged rather from the effects on sleep.

Sustained-release formulations different from Circadin ${ }^{\circledR}$ have been also tested with regard to their pharmakokinetics, including coated sugar spheres ${ }^{60}$ and solid lipid nanoparticles. ${ }^{61}$ However, their clinical use is not sufficiently established, so that they will not be considered here in detail.

Among the synthetic analogs that have been clinically tested, the investigative drug $\beta$-methyl-6-chloromelatonin (LY 156735) is that one most related to melatonin. This agonist developed by Eli Lilly also diplays a high affinity towards $\mathrm{MT}_{1}$ und $\mathrm{MT}_{2}$ receptors $\left(\mathrm{K}_{\mathrm{i}}=81 \mathrm{pM}\right.$ for $\mathrm{MT}_{1} \mathrm{bzw}$. $42 \mathrm{pM}$ for $\mathrm{MT}_{2}$ ). The preferential binding to $\mathrm{MT}_{2}$ is typical for the 6-chlorinated melatonin derivatives, and also seen with 6-chloromelatonin. ${ }^{47}$ Because of the substitution at 
C-atom 6, this drug cannot be converted by the respective CYP isoforms to 6-hydroxymelatonin and its half-life in the circulation is, therefore, extended. ${ }^{47,62}$ Although $\beta$-methyl-6chloromelatonin was effective in phase-shifting the circadian rhythm and showed sleep latency-reducing properties similar to those of melatonin, its effects on sleep maintenance remained marginal, even at doses of 20 or $100 \mathrm{mg},{ }^{47,62,63}$ so that this drug will not be further considered in this review.

Much more detailed information is available on a structurally dissimilar melatoninergic agonist, ramelteon $\left\{=\right.$ Rozerem $^{\circledR}=$ TAK-375 $=(\mathrm{S})-N$-[2-(1,6,7,8-tetrahydro-2H-indeno[5,4-b]furan-8-yl)ethyl]propionamide , produced by Takeda Pharmaceuticals Inc. This compound has been approved in 2005 by the FDA for treatment of insomnia in the USA. After a negative recommendation by EMEA, ${ }^{64}$ Takeda has withdrawn its European marketing authorization application in September $2008 .{ }^{65}$ The affinities of ramelteon to $\mathrm{MT}_{1}$ und $\mathrm{MT}_{2}$ receptors $\left(\mathrm{K}_{\mathrm{i}}=14 \mathrm{pM}\right.$ and $112 \mathrm{pM}$, respectively) are higher than those of melatonin (cf $\mathrm{K}_{\mathrm{i}}=80,7$ and $\left.383 \mathrm{pM}\right){ }^{46,66,67}$ Contrary to melatonin and other indolic analogs, such as $N$-acetylserotonin, it does not bind to quinone reductase 2 , at therapeutic doses $\left(\mathrm{K}_{\mathrm{i}}=2.65\right.$ $\mu \mathrm{M}$; cf melatonin: $\left.\mathrm{K}_{\mathrm{i}}=24 \mathrm{pM}\right) .{ }^{46}$ It displays very moderate binding to the serotonin receptor $5-\mathrm{HT}_{1 \mathrm{~A}}\left(\mathrm{~K}_{\mathrm{i}}=5.6 \mu \mathrm{M}\right)$, but virtually none to other 5 -HT receptor subtypes. Numerous other receptors, eg, for neurotransmitters, neuropeptides including endorphins have been tested and reported to have no substantial affinity. ${ }^{67}$ However, other melatonin binding sites, as mentioned above, have not been investigated.

Pharmacokinetics and metabolism of ramelteon have been studied in detail. It is rapidly taken up, reaching $\mathrm{T}_{\text {max }}$ between 0.75 and $0.94 \mathrm{~h}$, over a considerable dose range. ${ }^{68}$ Its half-life in the circulation amounts to about 1 to $2 \mathrm{~h}$ and is, therefore, considerably longer than that of melatonin. ${ }^{68}$ After escalating doses of $4,8,16,32$, and $64 \mathrm{mg}, \mathrm{C}_{\max }$ values of 1.15, 5.73, 6.92, 17.4, and $25.9 \mathrm{ng} / \mathrm{mL}$, and AUC values of 1.71, 6.95, 9.88, 22.5, and $36.1 \mathrm{ng} \times \mathrm{h} / \mathrm{mL}$ were obtained. ${ }^{68}$ Because of its structural dissimilarity, the metabolism of ramelteon fundamentally deviates from that of melatonin..$^{21,43,47,68}$ Although it is substrate to cytochrome $\mathrm{P}_{450}$ enzymes, including the melatoninhydroxylating CYP1A2, the products are substantially different. Four metabolites formed by CYP1A2, CYP2C and CYP3A are usually referred to as M-I, M-II, M-III und M-IV. Apart from cleavage of the tetrahydrofuran ring in M-I, hydroxylations and oxidations take place in positions not accessible in melatonin, either at a C-atom corresponding to the nitrogen in melatonin's pyrrole ring (M-III, M-IV) or at C-atom 2 of the propionyl residue of the aliphatic side chain (M-II, M-IV) (Figure 1). ${ }^{43,47}$
Because of the absence of a pyrrole ring, no kynuric metabolism is possible in the case of ramelteon. ${ }^{43,47}$

The properties of metabolite M-II are rather unusual and substantially contribute to the pharmacological activity of the parent compound. This is not particularly surprising, since M-II differs from ramelteon only by the hydroxyl group in the aliphatic side chain. On the one hand, this change reduces the affinities to $M T_{1}$ und $\mathrm{MT}_{2}$ receptors by a factor of about 10 , but, on the other hand, M-II itself is much less metabolized, has a half-life 2 to $5 \mathrm{~h}$ longer than the parent compound and can attain concentrations by 20- to 100-fold higher than ramelteon. ${ }^{68}$ Therefore, any pharmacokinetic consideration of ramelteon cannot be made without considering the long-lasting contribution of M-II. Consequently, judgments on the time course of action should not be restricted to $\mathrm{T}_{\max }, \mathrm{C}_{\max }$ and $\mathrm{AUC}$ values of ramelteon alone.

Another newly introduced synthetic melatoninergic agonist is tasimelteon $(=N-\{[(1 \mathrm{R}, 2 \mathrm{R})-2-(2,3-$ dihydro-1benzofuran-4-yl)cyclopropyl]methyl propanamide $=$ VEC162; earlier research codes: BMS-214778 and MA-1). This investigative drug is produced and being further developed by Vanda Pharmaceuticals, under license from BristolMyers Squibb Co. Binding and pharmacokinetic properties in humans have been disclosed only in part, although the company may possess more detailed information. According to unpublished information cited elsewhere, ${ }^{69}$ tasimelteon is selective for $\mathrm{MT}_{1}$ and $\mathrm{MT}_{2}$ receptors. In a web appendix, the following affinity data were presented: $\mathrm{pKi}=9.45 \pm 0.04$ $(0.35 \mathrm{nM})$ for $\mathrm{MT}_{1}$, and $\mathrm{pKi}=9.8 \pm 0.07(0.17 \mathrm{nM})$ for $\mathrm{MT}_{2},{ }^{70}$ without experimental details. After single oral doses between 10 and $100 \mathrm{mg}$, mean $\mathrm{T}_{\max }$ values varied from 1.9 to $3.0 \mathrm{~h}$, mean $\mathrm{C}_{\max }$ from 59.1 to $417.1 \mathrm{ng} / \mathrm{mL}$, and AUC from 171.1 to $1916.1 \mathrm{ng} \times \mathrm{h} / \mathrm{mL}$, however, with considerable interindividual deviations. ${ }^{70}$ More detailed pharmacokinetic data have been presented for rats and monkeys (Macaca fascicularis). ${ }^{71}$ These data indicate rapid uptake (monkeys, at moderate dose, $\mathrm{T}_{\max }$ in the range of $1 \mathrm{~h}$ ) and longer half-life than melatonin $\left(t_{1 / 2}\right.$ about 2 to $\left.3 \mathrm{~h}\right)$. A longer half-life mentioned elsewhere, without precise values, ${ }^{72}$ may have referred to the human. The metabolism, studied in rat, monkey and human liver, showed degradation by CYP1A1, CYP1A2, CYP2D6, and CYP2C9, and also some conjugation with glucuronic acid. ${ }^{71,73}$ Most of the metabolites have only been partially characterized and are, again, nonhomologous to those of melatonin (Figure 1), for fundamental reasons. Properties and kinetics of the tasimelteon metabolites are either unknown or not disclosed.

Agomelatine $\left\{=\right.$ Valdoxan $^{\circledR}=N$-[2-(7-methoxynaphth1-yl)ethyl]acetamide $=\mathrm{S} 20098\}$, developed by Servier, is 
also an agonist at $\mathrm{MT}_{1}$ and $\mathrm{MT}_{2}$ receptors $\left(\mathrm{K}_{\mathrm{i}}=61.5 \mathrm{pM}\right.$ and $268 \mathrm{pM}$, respectively), but additionally acts as a $5-\mathrm{HT}_{2 \mathrm{C}}$ receptor antagonist $\left(\mathrm{IC}_{50}=270 \mathrm{nM}\right)$, with low affinities to other 5-HT receptor subforms. ${ }^{21,43,47,74} 5-\mathrm{HT}_{2 \mathrm{C}}$ inhibition is largely responsible for the additional antidepressant action of this drug. The metabolism involving CYP1A1, CYP1A2, and CYP2C9 is partially different from that of melatonin (Figure 1). One main metabolite (S22153) is hydroxylated at the second ring carrying the long side chain, another one demethylated, corresponding to the formation of $N$-acetylserotonin from melatonin. The demethylated compound (S21517) resembles serotonin with regard to the presence of the hydroxyl group and, in fact, displays affinity to $5-\mathrm{HT}_{2 \mathrm{C}}{ }^{21,43}$ Since agomelatine is not exclusively a melatoninergic drug, it should not be regarded simply as a sleep-promoting compound suitable for treating an average insomniac, but may be of specific value in depressed patients. In February 2009, Valdoxan ${ }^{\circledR}$ was approved by EMEA for the treatment of major depressive episodes (MDE) in adults, ${ }^{75}$ but not generally as a hypnotic agent. Therefore, it will not be discussed here in any detail, despite its undoubtedly existing soporific actions.

\section{Efficacy of melatoninergic hypnotics}

All drugs mentioned in the previous section have been tested for their soporific potential. First of all, one has to distinguish between sleep-promoting effects in patients with CRSDs and others suffering from primary chronic insomnia. Any of the melatoninergic drugs is effective in phase-shifting circadian rhythms and, thus, seems suitable for treating jet lag and CRSDs, at least from the hypnotic point of view, but not necessarily under aspects of long-term safety. ${ }^{21,22,47,69}$ Since acute phase shifting and facilitation of sleep onset are also achieved by immediate-release melatonin, advantages of prolonged-release melatonin or longer-acting synthetic analogs should rather be sought in the treatment of primary chronic insomnia. $\beta$-Methyl-6-chloromelatonin was only marginally efficient in sleep maintenance, ${ }^{47,63,63}$ and, in terms of published evidence, tasimelteon has been only tested after artificial light-dark shifts. ${ }^{69}$ For reasons mentioned, the use of agomelatine should be only considered in conjunction with depression. Therefore, it seems primarily important to compare prolonged-release melatonin, such as Circadin ${ }^{\circledR}$, and its synthetic analog, ramelteon $\left(\right.$ Rozerem $\left.^{\circledR}\right)$, with a focus on primary chronic insomnia.

Studies on prolonged/extended-release melatonin have been conducted in the past using different preparations, sometimes referred to as controlled, sustained or slow release. Different doses had been used and some formulations contained combinations fast $(1 \mathrm{mg})$ and controlled-release components ( $4 \mathrm{mg}){ }^{76}$ The different studies are highly diverse, frequently of exploratory nature, or related to various disorders. Trials on larger numbers of subjects were only based on subjective measures. As compared to study design and detailed information on other hypnotics, the evidence is often circumstantial and sometimes contradictory. A conceptual diversity is even apparent in the material summarized by EMEA on Circadin ${ }^{\circledR} .{ }^{51}$ This material includes various exploratory and extended studies, including a phase III trial. The larger clinical studies on Circadin ${ }^{\circledR}, 51,77,78$ conducted on several hundred elderly patients (55 years and older) with primary insomnia are randomized, placebo-controlled and double-blind, but not generally with crossover design, and mainly based on questionnaires only (Leeds Sleep Evaluation Questionnaire = LSEQ; sometimes also Pittsburgh Sleep Quality Index = PSQI, WHO-5 well being index, and Clinical Global Improvement scale $=$ CGI). Taken together with exploratory studies also using polysomnography (PSG) or wrist actigraphy, ${ }^{51,79}$ the data collectively show that prolonged-release melatonin/Circadin ${ }^{\circledR}$ significantly reduces sleep onset latency (SOL), whereas direct evidence for the support of sleep maintenance and total sleep time is poor. Changes in awakenings from sleep are sometimes not statistically demonstrable, but may be deduced from patients' reports on improvements of sleep quality. ${ }^{51,77,78}$ More direct support, based on objective measures, for this important aspect of primary insomnia would be welcome. It should be also mentioned that the percentage of nonresponders to melatonin was substantial. ${ }^{51}$ In this context, the improvements obtained by the prolonged-release formulation should be decisive. Reductions in sleep latency are well known for fast-release melatonin, and have to be also expected for prolonged-release pills, especially as the amounts required for promoting sleep initiation are relatively low. ${ }^{80,81}$ Since the development of prolonged-release melatonin was aiming to support sleep maintenance, especially in patients with primary chronic insomnia, the most relevant parameters should be reductions in number or duration of awakenings from sleep and improvements of total sleep time. To convincingly demonstrate efficacy in sleep maintenance, more data on objective measures are required. However, there is a good reason for assuming that improvements in sleep quality and efficiency will be also demonstrable according to hard criteria, insofar as the subjective improvements were particularly evident in patients with severe or very severe forms of primary insomnia as well as in a subpopulation of poor melatonin secretors, as identified by low urinary 6-sulfatoxymelatonin levels. ${ }^{51,78}$ 
Therefore, Circadin ${ }^{\circledR}$ or other prolonged-release formulations of melatonin may be suitable for replacement therapy, eg, in patients with age-related decreases in nocturnal melatonin secretion.

Additional information on prolonged-/controlled-release melatonin is available from studies on treatment jet lag, shift work and various disorders, sometimes including comparisons with fast-release melatonin. In jet lag, ${ }^{80-82}$ not unexpectedly, either formulation proved to be effective. A meta-analysis of 10 studies revealed, however, a superiority of fast-release melatonin. ${ }^{81} \mathrm{~A}$ study on aircrews on transatlantic flights, based on both subjective measures and wrist actigraphy, reported a relatively good efficacy of $2 \mathrm{mg}$ sustained-release melatonin. ${ }^{82}$ In addition to reductions in sleep latency, improvements concerning number and duration of awakenings after sleep onset, quality of sleep and facilitation of returning to sleep were demonstrated.

Studies on simulated shift work ${ }^{83,84}$ were affected by the problem of melatonin administration in unfavorable circadian phases and are, thus, difficult to compare. The efficacy of sustained-release melatonin was also studied in children and young adults with CRSDs ${ }^{76,85}$ and with neurodevelopmental disabilities. ${ }^{76,86-94}$ Improvements were reported, but data on sleep initiation were either not provided or, in part, insufficient. The clearest results were obtained in the most recent study using $5 \mathrm{mg}$ controlled-release melatonin tablets. ${ }^{86}$ With this higher dosage, reductions in sleep latency and rises in night-time sleep duration were demonstrated by both subjective measures and wrist actigraphy. In children with autism, an open-label study, based on the Children's Sleep Habits Questionnaire and diary, improvements were obtained with controlled-release melatonin. ${ }^{95}$ Some circumstantial evidence for sleep improvements were reported for depressed patients, ${ }^{96,97}$ but without changes in the Hamilton Rating Score for Depression. ${ }^{97}$ Positive results were also obtained in intensive-care patients with chronic obstructive pulmonary disease or pneumonia. ${ }^{98}$ In a subpopulation of schizophrenics, improvements of sleep were reported, ${ }^{99}$ but not after sleep disturbance by the so-called first night effect in a sleep laboratory. ${ }^{100}$ Although some smaller studies indicated sleep improvements by melatonin in patients with Alzheimer's disease, as previously summarized, ${ }^{6}$ neither $2.5 \mathrm{mg}^{4}$ nor $6 \mathrm{mg}^{101}$ sustained-release nor $10 \mathrm{mg}$ immediate-release ${ }^{4}$ melatonin resulted in statistically significant improvements, perhaps an indication for the heterogeneity of these populations.

Compared to prolonged-release melatonin, the outcome of trials on ramelteon is much more uniform, as becomes evident from recent summaries. ${ }^{20-22,102,103}$ Collectively, all the data unanimously show that ramelteon, at doses of 4 or $8 \mathrm{mg}$, not only reduces sleep onset latency, but also improves total sleep time and sleep efficiency/sleep quality. This has also been demonstrated in several double-blind, placebocontrolled studies on a total of more than a thousand adult or elderly subjects with primary chronic insomnia. ${ }^{104-107}$ All the effects were statistically significant, but the improvements of sleep maintenance remained moderate. In accordance with the higher receptor affinities of ramelteon compared to melatonin, no further improvements were obtained with 16 or $32 \mathrm{mg}$ daily. ${ }^{105,107}$ Moreover, ramelteon did not worsen sleep apnea, ${ }^{108}$ in accordance with the lack of generalized central nervous suppression, as would occur with GABAergic agonists. According to the available data for recommended doses (usually $8 \mathrm{mg}$ ), ramelteon seems to be somewhat more effective than prolonged-release melatonin in the treatment of primary chronic insomnia, as far as sleep maintenance is concerned. Several factors should contribute to this finding: (i) higher receptor affinities to both melatonin receptors, especially to $\mathrm{MT}_{1}$; (ii) higher bioavailability because of longer half-life; (iii) a long-lasting contribution of the metabolite M-II; and (iv) the higher recommended doses of 4 or $8 \mathrm{mg}$ ramelteon vs $2 \mathrm{mg}$ Circadin $^{\circledR}$. Nevertheless, EMEA found the efficacy of ramelteon in improving sleep maintenance insufficient for a marketing authorization. ${ }^{64}$

\section{Safety, tolerability, withdrawal}

In full agreement with numerous findings on immediaterelease melatonin, all studies on the prolonged-release formulation unanimously show that the recommended dose does not cause next-day hangover, but rather favors morning alertness - although some exceptions have been described in other investigations using different doses. It does not lead to dependence, early or late withdrawal effects after discontinuation. ${ }^{51,77-79}$ The development of tolerance is usually absent with melatonin, although a few exceptions have been reported, especially in some children with neurological disorders. ${ }^{91-94}$ Should the development of tolerance turn out to be a consequence of altered metabolism, which remains to be demonstrated, other melatoninergic agonists might be tested. A recent randomized, double-blind, placebocontrolled crossover study on prolonged-release melatonin confirmed the absence of next-day impairments of psychomotor functions, driving skills and memory recall, in contrast to $10 \mathrm{mg}$ zolpidem. ${ }^{109}$ Controlled-release melatonin (2 mg) was successfully used even for facilitating benzodiazepine discontinuation. ${ }^{110}$ 
Like melatonin, ramelteon did not cause next-day hangover (as revealed by subjective feeling, psychomotor and cognitive tests, and ability to concentrate) ${ }^{105}$ rebound insomnia or other withdrawal effects, or development of tolerance or addiction. ${ }^{20-22,105}$ Under these conditions, both prolonged-release melatonin and ramelteon appear safe in short-term treatment, as may be assumed for other exclusively melatoninergic drugs in general.

For subjective criteria of adverse effects, such as reports of nausea, digestive difficulties, headache or other pain, dizziness, and mood, no substantial differences were detected between Circadin ${ }^{\circledR}$ and placebo, and frequently trends were detected even towards fewer subjective side effects in the melatonin groups. ${ }^{51}$ In this context, it should be also noted that considerably higher doses of melatonin, $300 \mathrm{mg} /$ day enterally, were administered for up to 2 years to amyotrophic lateral sclerosis patients and found to be safe. ${ }^{111}$ Subjective reports of adverse effects showed that ramelteon 4 or $8 \mathrm{mg}$ was also well tolerated, with similar outcomes as for placebo. ${ }^{20,21,104-107}$

Precautions should be taken with both melatonin and ramelteon for other reasons. First, the use of a melatoninergic agonist should be restricted to appropriate circadian phases in the evening, since it may cause drowsiness when taken during daytime and, in this case, may in fact impair psychomotor functions, including driving skills. While the use of hypnotics should anyway be restricted to bedtime, more specific precautions are related to the pleiotropy ${ }^{19,45}$ of melatonin. It is of utmost importance to keep in mind that melatonin is not just a hormone transmitting the darkness signal, and not only a regulator affecting the $\mathrm{SCN}$, but rather influences numerous additional functions. ${ }^{19,43-45,49}$ Even for ramelteon, which may exclusively act on $\mathrm{MT}_{1}$ and $\mathrm{MT}_{2}$ receptors (although this selectivity has not been demonstrated for the newly discovered binding sites), various effects beyond $\mathrm{SCN}$ modulaton and sleep promotion have to be expected. This would include influences on other hormones, and on the immune system, vasculature, and the gastrointestinal system. The possibility of undesired melatoninergic effects on the reproduction system may be a controversial issue. The respective influences of the hormone are without any doubt not comparable to those in seasonal breeders, but, on the other hand, earlier attempts to use melatonin as a contraceptive, ${ }^{112-114}$ suppressive effects on the GnRH pulse generator ${ }^{15}$ and deviations of melatonin in reproductive disorders ${ }^{116-118}$ have been seen as a caveat in the opinion of some investigators and also of EMEA. ${ }^{51}$ Especially in reproductive disorders, changes in melatonin may not be causative, but rather consequences of other anatomical or physiological disturbances. In perimenopausal women, effects of melatonin on LH, FSH and thyroid hormones were observed, ${ }^{119}$ whereas no changes were detected in $\mathrm{LH}$, $\mathrm{FSH}$, testosterone and inhibin- $\beta$ in normal men subjected to long-term treatment with the pineal hormone. ${ }^{120}$ However, melatonin was also reported to decrease semen quality in two healthy men, ${ }^{121}$ but this study was conducted with a very small number of volunteers. Concerns because of changes in the reproductive system may be taken as a contraindication for treating children, adolescents and pregnant women with melatonin, as did EMEA in the case of Circadin ${ }^{\circledR} .{ }^{51}$ On the other hand, children, adolescents and young adults have been treated for considerable periods of time with the pineal hormone, without reports of undesired effects in the reproductive system. ${ }^{14,76,85,95,122-124}$ The position of EMEA, which has approved Circadin ${ }^{\circledR}$ only for subjects of 55 years and older, ${ }^{51}$ may appear unduly cautious, but EMEA intends to be cautious. Nevertheless, melatonin formulations or other melatoninergic drugs should be an option for children with severe and otherwise intractable neurological disorders.

Precautions are necessary in subjects with immunological disorders, since melatonin is also a mainly stimulatory immunomodulator. ${ }^{19,45,49}$ Thus, melatoninergic drugs should generally not be prescribed to patients with autoimmune diseases. ${ }^{51}$ With both melatonin and ramelteon, another caveat concerns drugs influencing cytochrome $\mathrm{P}_{450}$ enzymes, especially inhibitors of CYP1A2, ${ }^{20,47,48,51}$ such as fluvoxamine, which would lead to substantial rises in circulating melatonin and ramelteon as well. Additional specific precautions are listed for Circadin ${ }^{\circledR}$, such as LAPP lactase deficiency and glucose-galactose malabsorption, ${ }^{51}$ and for ramelteon concerning alcohol, high-fat diet and renal impairment. ${ }^{20,125}$

Another disorder that may be regarded as a contraindication against the use of melatoninergic agonists is Parkinson's disease (PD). Contrary to findings in various animal models, melatonin has not been generally beneficial in PD patients, especially for disease progression, as summarized earlier. ${ }^{6}$ More recently, PD has been interpreted as an endocrine disorder characterized by melatonin hyperplasia. ${ }^{126}$ Correspondingly, clinical improvements have been obtained by melatonin antagonist treatment. ${ }^{127}$ Melatonin hyperplasia may also deserve attention in other diseases, eg, irritable bowel syndrome type II, in which an enhanced proliferation of melatonin and serotonin producing cells is observed, in conjunction with losses of other cell types. ${ }^{128}$

At recommended doses ${ }^{51}$ and even higher, melatonin is devoid of mutagenicity or carcinogenicity, but instead 
appears to be protective in this regard..$^{38,44,49,55,129}$ The absence of genotoxicity and carcinogenicity is also reported for ramelteon. ${ }^{125}$ However, some reservations seem appropriate with this drug, ${ }^{20,21,47}$ since the no-effect level for induction of hepatic tumors in male mice was only three times the concentration of the metabolite M-II measured after the therapeutic dose. ${ }^{125}$ Moreover, micronuclei formations were observed in Chinese hamster lung cells after metabolic activation. ${ }^{125}$ The naphthalenic compound agomelatine may require further toxicological studies. ${ }^{21,47}$ In this place, it should be emphasized that safety studies also have to consider the properties of the metabolites, which is not generally sufficiently done. For the metabolites of melatonin, one can state that they never attain high concentrations. Kynuric products, which may be relevant in tissues, have been reported to be protective rather than deleterious. ${ }^{38,44,129}$ More extensive studies on properties of metabolites are necessary for any of the synthetic melatoninergic drugs, including $\beta$-methyl-6-chloromelatonin, tasimelteon and agomelatine, in the last case also for the serotonin analog S 21517, ${ }^{21}$ and, most importantly, for the ramelteon metabolite $\mathrm{M}$-II, because of the high concentrations attained and its long half-life in the circulation.

In summary, both prolonged-release melatonin and ramelteon are well tolerated and safe in the populations indicated by the respective approvals, and acceptable for short-term treatment. Experience with the extended high-dose melatonin treatment in ALS patients ${ }^{111}$ indicates that Circadin $^{\circledR}$ may be safe even for prolonged treatment, whereas more studies would be required for ramelteon to be sure about this point. ${ }^{20,21,47}$

\section{Conclusions, place in therapy}

Melatonin and all synthetic melatoninergic drugs discussed here are capable of phase shifting the circadian pacemaker, and all of them can be expected to reduce sleep onset latency, with the exception of a certain number of nonresponders. In terms of toxicology, beyond the subjective reports on absence or presence of adverse effects, $\beta$-methyl- 6 -chloromelatonin, ramelteon, tasimelteon and agomelatine need further investigation for long-term safety, particularly for tasimelteon, which is administered in relatively high doses of 20 or $50 \mathrm{mg}$, ${ }^{69}$ compared with the much lower doses of ramelteon $(8 \mathrm{mg})$ or melatonin $(2 \mathrm{mg})$. The nonselective drug agomelatine may be useful in major depressive disorder, ${ }^{21,47}$ but, alternatively, combinations of classic antidepressants with z-drugs such as zolpidem extended-release may be likewise effective. ${ }^{130}$

With these reservations, all the chronobiotics, but more in particular, the approved hypnotics Circadin ${ }^{\circledR}$ (melatonin prolonged release) and Rozerem ${ }^{\circledR}$ (ramelteon), but presumably also the investigative drug tasimelteon, ${ }^{69}$ should be suitable for treating jet lag or other phase shifts, and also tractable forms of CRSDs, such as DSPS and FASPS. Beyond phase resetting, facilitation of sleep onset can be expected in mild types of CRDS-related insomnia. In this regard, one might, however, ask whether a prolonged-release formulation or a drug of longer half-life and higher receptor affinity is really needed. Sleep onset can be even promoted by 0.1 or $0.3 \mathrm{mg}$ immediaterelease melatonin, ${ }^{20}$ so that a higher dose may not be required in these cases, nor prolonged release, longer half-life or higher receptor affinity. Circadin ${ }^{\circledR}$ or Rozerem ${ }^{\circledR}$ may be tested, if immediate-release melatonin fails.

The situation is different in primary chronic insomnia, in which a substantial support of sleep maintenance is required. In this disorder, statistically significant but still moderate effects of ramelteon have been reported, ${ }^{20-22,47,102-107}$ whereas prolonged-release melatonin would require substantiation of its efficacy. Such a comparison should, however, consider the differences in recommended doses. Although ramelteon has considerably higher receptor affinities and a relatively longer half-life, 4 or $8 \mathrm{mg}$ are recommended, whereas only $2 \mathrm{mg}$ of melatonin are present in a Circadin ${ }^{\circledR}$ tablet. It seems inappropriate to be extremely cautious with the natural compound melatonin, which is exceptionally well tolerated in the majority of individuals, but not to apply the same criteria to a longer-acting synthetic analog with higher receptor affinity. ${ }^{47}$

Treatment with melatoninergic agonists seems to be promising in another disorder, Smith-Magenis syndrome, which is characterized, apart from developmental and neurobehavioral abnormalities, by a largely inverted melatonin rhythm and sleep difficulties. ${ }^{87,88}$ In this case, a combination of a $\beta_{1}$-adrenergic blocker in the morning, to suppress diurnal melatonin secretion, and melatonin in the evening has been applied with some success. ${ }^{89,90}$ In this congenital disease, a sustained high nocturnal level of melatonin would be of particular importance, which indicates the use of a prolonged-release formulation. Whether or not melatonin may be replaced by synthetic agonists such as ramelteon remains to be clarified and may depend on long-term safety. Other neurodevelopmental and neuropsychiatric disorders associated with sleep difficulties or CRSDs, which have been studied in children and young adults and are sometimes otherwise intractable, ${ }^{76,85,86,91-94}$ may be seen as an additional area of treatment, despite the reservations of EMEA.

Nevertheless, caution should go beyond the risks mentioned in the previous section, such as autoimmune diseases, Parkinson's disease, coadministration of CYP inhibitors, 
and hepatic and renal diseases. Surveillance seems to be appropriate for the development and function of reproductive organs. Pregnancy would be another condition under which benefits and possible risks have to be weighed. These considerations should equally apply to melatonin prolonged or immediate-release, ramelteon and other melatoninergic drugs. Therefore, the decision by EMEA to approve Circadin ${ }^{\circledR}$ for subjects older than 54 years, along with a list of specific precautions, is a responsible one, although it may appear unduly cautious. The same criteria should be applied to ramelteon, and to other melatoninergic drugs that may be evaluated for approval.

Nevertheless, all melatoninergic drugs discussed are well tolerated in short-term treatment, and for the natural compound, melatonin, the same should be valid for long-term administration, except for the precautions mentioned above.

Melatonin and its synthetic analogs may be helpful even in other disorders, such as relieving sleep difficulties caused by benzodiazepine discontinuation ${ }^{110}$ and in chronic obstructive pulmonary disorder, in which ramelteon has been shown to be effective, ${ }^{131,132}$ and for which the same may be valid in the case of melatonin. ${ }^{98,133}$

In practical terms, sleep difficulties should first be tested for causes related to circadian dysfunction, in which immediate-release melatonin may already be effective, and Circadin ${ }^{\circledR}$ should be tried if the immediate-release formulation does not suffice. In cases of chronic primary insomnia, ramelteon seems, according to current knowledge, slightly more promising than prolonged-release melatonin. If melatoninergic drugs fail, z-drugs may be the better option. In patients of appropriate age and not belonging to a risk group, the general strategy may be to first test the natural compound, melatonin, because of its remarkable tolerability and safety, before other options are used.

\section{Disclosures}

The author has no conflicts of interest to declare.

\section{References}

1. American Psychiatric Association. Diagnostic and statistical manual of mental disorders. 4th edition (DSM-IV), text revision. Washington, DC: American Psychiatric Association; 2000.

2. Drake CL, Roehrs T, Roth T. Insomnia causes, consequences, and therapeutics: an overview. Depress Anxiety. 2003;18:163-176.

3. National Institutes of Health. NIH statement regarding the treatment of insomnia. State of the Science Conference Statement: Manifestations and management of chronic insomnia ind adults. Sleep. 2005;28: 1049-1057.

4. Singer C, Tractenberg RE, Kaye J, Schafer K, Gamst A, Grundman M, et al. A multicenter, placebo-controlled trial of melatonin for sleep disturbance in Alzheimer's disease. Sleep. 2003;26:893-901.
5. Skene DJ, Swaab DF. Melatonin rhythmicity: effect of age and Alzheimer's disease. Exp Gerontol. 2003;38:199-206.

6. Srinivasan V, Pandi-Perumal SR, Cardinali DP, Poeggeler B, Hardeland R. Melatonin in Alzheimer's disease and other neurodegenerative disorders. Behav Brain Funct. 2006;2:15.

7. Wu YH, Swaab DF. Disturbance and strategies for reactivation of the circadian rhythm system in aging and Alzheimer's disease. Sleep Med. 2007;8:623-636.

8. Lockley SW, Skene DJ, Butler LJ, Arendt J. Sleep and activity rhythms are related to circadian phase in the blind. Sleep. 1999;22:616-623.

9. Ebisawa T. Circadian rhythms in the CNS and peripheral clock disorders: human sleep disorders and clock genes. J Pharmacol Sci. 2007;103:150-154.

10. Okawa M, Uchiyama M. Circadian rhythm sleep disorders and entrainment pathology in delayed sleep phase and non-24-h sleep-wake syndrome. Sleep Med Rev. 2007;11:485-496.

11. Skene DJ, Lockley SW, Arendt J. Use of melatonin in the treatment of phase shift and sleep disorders. Adv Exp Med Biol. 1999;467:79-84.

12. Kamei Y, Hayakawa T, Urata J, Uchiyama M, Shibui K, Kim K, et al. Melatonin treatment for circadian rhythm sleep disorders. Psychiatry Clin Neurosci. 2000;54:391-392.

13. Zisapel N. Circadian sleep disorders: pathophysiology and potential approaches to management. CNS Drugs. 2001;15:311-328.

14. Szeinberg A, Borodkin A, Dagan Y. Melatonin treatment in adolescents with delayed sleep phase syndrome. Clin Pediatr (Phila). 2006;45:809-818.

15. Liu C, Weaver DR, Jin X, Shearman LP, Pieschl RL, Gribkoff VK, et al. Molecular dissection of two distinct actions of melatonin on the suprachiasmatic clock. Neuron. 1997;19:91-102.

16. von Gall C, Stehle JH, Weaver DR. Mammalian melatonin receptors: molecular biology and signal transduction. Cell Tissue Res. 2002;309:151-162.

17. Jin X, von Gall C, Pieschl RL, Gribkoff VK, Stehle JH, Reppert SM, et al. Targeted disruption of the mouse $\mathrm{Mel}_{1 \mathrm{~b}}$ melatonin receptor. Mol Cell Biol. 2003;23:1054-1060.

18. Dubocovich ML, Markowska M. Functional $\mathrm{MT}_{1}$ and $\mathrm{MT}_{2}$ melatonin receptors in mammals. Endocrine. 2005;27:101-110.

19. Hardeland R. Melatonin: Signaling mechanisms of a pleiotropic agent. BioFactors. 2009;35:183-192.

20. Pandi-Perumal SR, Srinivasan V, Poeggeler B, Hardeland R, Cardinali DP. Drug insight: the use of melatonergic agonists for the treatment of insomnia - focus on ramelteon. Nat Clin Pract Neurol. 2007:3:221-228.

21. Hardeland R, Poeggeler B, Srinivasan V, Trakht I, Pandi-Perumal SR, Cardinali DP. Melatonergic drugs in clinical practice. Arzneimittelforschung. 2008;58:1-10.

22. Srinivasan V, Pandi-Perumal SR, Trahkt I, Spence DW, Poeggeler B, Hardeland R, et al. Melatonin and melatonergic drugs on sleep: possible mechanisms of action. Int J Neurosci. 2009;119:821-846.

23. Saper CB, Scammell TE, Lu J. Hypothalamic regulation of sleep and circadian rhythms. Nature. 2005;437:1257-1263.

24. Fuller PM, Gooley JJ, Saper CB. Neurobiology of sleep-wake cycle, sleep architecture, circadian regulation and regulatory feed back. J Biol Rhythms. 2006;21:482-493.

25. Reppert SM, Godson C, Mahle CD, Weaver DR, Slaugenhaupt SA, Gusella JF. Molecular characterization of a second melatonin receptor expressed in human retina and brain: the Mel1b melatonin receptor. Proc Natl Acad Sci U S A. 1995;92:8734-8738.

26. Mazzucchelli C, Pannacci M, Nonno R, Lucini V, Fraschini F, Stankov BM. The melatonin receptor in the human brain: cloning experiments and distribution studies. Brain Res Mol Brain Res. 1996;39:117-126.

27. Thomas L, Purvis CC, Drew JE, Abramovich DR, Williams LM. Melatonin receptors in human fetal brain: 2-[125I]iodomelatonin binding and $\mathrm{MT}_{1}$ gene expression. J Pineal Res. 2002;33:218-224.

28. Ambriz-Tututi M, Rocha-González HI, Cruz SL, Granados-Soto V. Melatonin: A hormone that modulates pain. Life Sci. 2009;84:489-498. 
29. Dijk DJ, Roth C, Landolt HP, Werth E, Aeppli M, Achermann P, et al. Melatonin effect on daytime sleep in men: suppression of EEG low frequency activity and enhancement of spindle frequency activity. Neurosci Lett. 1995;201:13-16.

30. Jan JE, Reiter RJ, Wasdell MB, Bax M. The role of the thalamus in sleep, pineal melatonin production, and circadian rhythm sleep disorders. J Pineal Res. 2009;46:1-7.

31. De Gennaro L, Ferrara M. Sleep spindles. An overview. Sleep Med Rev. 2003;7:423-440.

32. Morin LP, Allen CN. The circadian visual system, 2005. Brain Res Rev. 2006;51:1-60.

33. Jan JE, Wasdell MB, Reiter RJ, Weiss MD, Johnson KP, Ivanenko A, et al. Melatonin therapy of pediatric sleep disorders: recent advances, why it works, who are the candidates and how to treat. Curr Pediatr Rev. 2007;3:214-224.

34. Cajochen C, Münch M, Knoblauch V, Blatter K, Wirz-Justice A. Age-related changes in the circadian and homeostatic regulation of human sleep. Chronobiol Int. 2006;23:461-474.

35. Gorfine T, Zisapel N. Late evening brain activation patterns and their relation to the internal biological time, melatonin, and homeostatic sleep debt. Hum Brain Mapp. 2009;30:541-552.

36. Dijk DJ, von Schantz M. Timing and consolidation of human sleep, wakefulness, and performance by a symphony of oscillators. $J$ Biol Rhythms. 2005;20:279-290.

37. Cajochen C, Kräuchi K, Wirz-Justice A. Role of melatonin in the regulation of human circadian rhythms and sleep. J Neuroendocrinol. 2003; 15:432-437.

38. Hardeland R. Antioxidative protection by melatonin - Multiplicity of mechanisms from radical detoxification to radical avoidance. Endocrine. 2005;27:119-130.

39. Lu J, Sherman D, Devor M, Saper CB. A putative flip-flop switch for control of REM sleep. Nature. 2006;441:589-594.

40. Fuller PM, Saper CB, Lu J. The pontine REM switch: past and present. J Physiol. 2007;584:735-741.

41. Kunz D, Mahlberg R, Müller C, Tilmann A, Bes F. Melatonin in patients with reduced REM sleep duration: two randomized controlled trials. J Clin Endocrinol Metab. 2004;89:128-134.

42. Claustrat B, Brun J, Chazot G. The basic physiology and pathophysiology of melatonin. Sleep Med Rev. 2005;9:11-24.

43. Hardeland R, Poeggeler B. Actions of melatonin, its structural and functional analogs in the central nervous system and the significance of metabolism. Cent Nerv Syst Agents Med Chem. 1007;7: 289-303.

44. Hardeland R, Poeggeler B. Melatonin beyond its classical functions. Open Physiol J. 2008;1:1-23.

45. Hardeland R. Melatonin, hormone of darkness and more-occurrence, control mechanisms, actions and bioactive metabolites. Cell Mol Life Sci. 2008;65:2001-2018.

46. Kato K, Hirai K, Nishiyama K, Uchikawa O, Fukatsu K, Ohkawa S, et al. Neurochemical properties of ramelteon (TAK-375), a selective $\mathrm{MT}_{1} / \mathrm{MT}_{2}$ receptor agonist. Neuropharmacology. 2005;48:301-310.

47. Poeggeler B, Hardeland R. Melatoninerge Chronobiotika: Wirkungen und Probleme. In: Hardeland R, editor. Facetten der Chronobiologie. Abh Leibniz-Soz, Vol 23. Berlin: Trafo; 2008. p. 71-87.

48. Ma X, Idle JR, Krausz KW, Gonzalez FJ. Metabolism of melatonin by human cytochromes p450. Drug Metab Dispos. 2005;33: 489-494.

49. Pandi-Perumal SR, Srinivasan V, Maestroni GJM, Cardinali DP, Poeggeler B, Hardeland R. Melatonin - Nature's most versatile biological signal? FEBS J. 2006;273:2813-2838.

50. Feldstein A, Chang FH, Kucharski JM. Tryptophol, 5-hydroxytryptophol and 5-methoxytryptophol induced sleep in mice. Life Sci. 1970;9: 323-329.

51. EMEA. Assessment report for Circadin. 2007;52 p. Available from: http.//www.emea.europe.eu/humandocs/PDFs/EPAR/Circadin/ H-695-eu6.pdf.
52. Huether G, Messner M, Rodenbeck A, Hardeland R. Effect of continuous melatonin infusions on steady-state plasma melatonin levels in rats under near physiological conditions. J Pineal Res. 1998;24:146-151.

53. Hajak G, Huether G, Blanke J, Blömer M, Freyer C, Poeggeler B, et al. The influence of intravenous L-tryptophan on plasma melatonin and sleep in men. Pharmacopsychiatry. 1991;24:17-20.

54. Bubenik GA. Gastrointestinal melatonin: localization, function, and clinical relevance. Dig Dis Sci. 2002;47:2336-2348.

55. Hardeland R, Pandi-Perumal SR. Melatonin, a potent agent in antioxidative defense: Actions as a natural food constituent, gastrointestinal factor, drug and prodrug. Nutr Metab (Lond). 2, 2005; article no 22 [DOI 10.1186/1743-7075-2-22].

56. Poeggeler B, Cornélissen G, Huether G, Hardeland R, Józsa R, Zeman M, et al. Chronomics affirm extending scope of lead in phase of duodenal vs pineal circadian melatonin rhythms. Biomed Pharmacother. 2005;59:S220-S224.

57. Tan DX, Manchester LC, Reiter RJ, Qi W, Hanes MA, Farley NJ. High physiological levels of melatonin in the bile of mammals. Life Sci. 1999;65:2523-2529.

58. Messner M, Huether G, Lorf T, Ramadori G, Schwörer H. Presence of melatonin in the human hepatobiliary-gastrointestinal tract. Life Sci. 2001;69:543-551.

59. Huether G. Melatonin synthesis in the gastrointestinal tract and the impact of nutritional factors on circulating melatonin. Ann N Y Acad Sci. 1994;719:146-158.

60. Lee BJ, Ryu SG, Choi HG, Kim CK, Parrott KA, Ayres JW, et al. Batch variation and pharmacokinetics of oral sustained release melatonin-loaded sugar spheres in human subjects. Arch Pharm Res. 1997;20:555-559.

61. Priano L, Esposti D, Esposti R, Castagna G, De Medici C, Fraschini F, et al. Solid lipid nanoparticles incorporating melatonin as new model for sustained oral and transdermal delivery systems. $J$ Nanosci Nanotechnol. 2007;7:3596-3601.

62. Mulchahey JJ, Goldwater DR, Zemlan FP. A single blind, placebo controlled, across groups dose escalation study of the safety, tolerability, pharmacokinetics and pharmacodynamics of the melatonin analog $\beta$-methyl-6-chloromelatonin. Life Sci. 2004;75:1843-1856.

63. Zemlan FP, Mulchahey JJ, Scharf MB, Mayleben DW, Rosenberg R, Lankford A. The efficacy and safety of the melatonin agonist $\beta$-methyl-6chloromelatonin in primary insomnia: a randomized, placebo-controlled, crossover clinical trial. J Clin Psychiatry. 2005;66:384-390.

64. EMEA. Questions and answers on recommendation for the refusal of the marketing authorisation for ramelteon. Press Release, May 30, 2008. http://www.emea.europa.eu/pdfs/human/opinion/ Ramelteon_26821608en.pdf.

65. EMEA. Takeda withdraws its marketing authorisation application for Ramelteon. Press Release, September 25, 2008. http://www.emea. europa.eu/humandocs/PDFs/EPAR/ramelteon/50471608en.pdf.

66. Miyamoto M, Nishikawa $\mathrm{H}$, Ohta $\mathrm{H}$, Uchikawa O, Ohkawa O, Ohkawa S. Behavioural pharmacology of TAK-375 in small animals. Ann Neurol. 2003;54:S46.

67. McGechan A, Wellington K. Ramelteon. CNS Drugs. 2005;19:1057-1065.

68. Karim A, Tolbert D, Cao C. Disposition kinetics and tolerance of escalating single doses of ramelteon, a high affinity $\mathrm{MT}_{1}$ and $\mathrm{MT}_{2}$ melatonin receptor agonist indicated for the treatment of insomnia. J Clin Pharmacol. 2006;46:140-148.

69. Rajaratnam SM, Polymeropoulos MH, Fisher DM, Roth T, Scott C, Birznieks G, et al. Melatonin agonist tasimelteon (VEC-162) for transient insomnia after sleep-time shift: two randomised controlled multicentre trials. Lancet. 2009;373:482-491.

70. Klerman EB Melatonin agonist tasimelteon (VEC-162) for transient insomnia after sleep-time shift: two randomised controlled multicentre trials. Web Appendix to online prepublication of ref. 53. 2008;www. thelancet.com. 
71. Vachharajani NN, Yeleswaram K, Boulton DW. Preclinical pharmacokinetics and metabolism of BMS-214778, a novel melatonin receptor agonist. J Pharm Sci. 2003;92:760-772.

72. IDdb Author. Associated Professional Sleep Societies - 20 Annual Meeting (Part I), Hypnotic and Wake-promoting Drugs, Salt Lake City, UT, USA. IDdb Meeting Report; 2006, June 17-22.

73. Zhu M, Mitroka J, Shaw AA, Luke GM, Vachharajani N, Kripalani KJ. Identification of in vitro and in vivo metabolites of BMS-214778 in monkeys by ion trap LC/MS and LC/NMR. Drug Metab Rev. 2000;32 Suppl 2:260.

74. Millan MJ, Gobert A, Lejeune F, Dekeyne A, Newman-Tancredi A, Pasteau V, et al. The novel melatonin agonist agomelatine (S20098) is an antagonist at 5-hydroxytryptamine ${ }_{2 \mathrm{C}}$ receptors, blockade of which enhances the activity of frontocortical dopaminergic and adrenergic pathways. J Pharmacol Exp Ther. 2003;306:954-964.

75. Servier Pharma. Valdoxan ${ }^{\circledR}$ (agomelatine), a novel antidepressant, receives European marketing authorization. Servier Press Release. 2009;http://www.agomelatine.org/2009-valdoxan.html.

76. Carr R, Wasdell MB, Hamilton D, Weiss MD, Freeman RD, Tai J, et al. Long-term effectiveness outcome of melatonin therapy in children with treatment-resistant circadian rhythm sleep disorders. J Pineal Res. 2007;43:351-359.

77. Wade AG, Ford I, Crawford G, McMahon AD, Nir T, Laudon M, et al. Efficacy of prolonged release melatonin in insomnia patients aged 55-80 years: quality of sleep and next-day alertness outcomes. Curr Med Res Opin. 2007;23:2597-2605.

78. Lemoine P, Nir T, Laudon M, Zisapel N. Prolonged-release melatonin improves sleep quality and morning alertness in insomnia patients aged 55 years and older and has no withdrawal effects. J Sleep Res 2007;16:372-380.

79. Haimov I, Lavie P, Laudon M, Herer P, Vigder C, Zisapel N. Melatonin replacement therapy of elderly insomniacs. Sleep. 1995;18:598-603.

80. Suhner A, Schlagenhauf P, Johnson R, Tschopp A, Steffen R. Comparative study to determine the optimal melatonin dosage form for the alleviation of jet lag. Chronobiol Int. 1998;15:655-666.

81. Herxheimer A, Petrie KKJ. Melatonin for the prevention and treatment of jet lag. Cochrane Database Syst Rev. 2002;(2): article no. CD001520. DOI: 10.1002/14651858.CD001520.

82. Paul MA, Gray G, Sardana TM, Pigeau RA. Melatonin and zopiclone as facilitators of early circadian sleep in operational air transport crews. Aviat Space Environ Med. 2004;75:439-443.

83. Sharkey KM, Fogg LF, Eastman CI. Effects of melatonin administration on daytime sleep after simulated night shift work. J Sleep Res. 2001;10:181-192.

84. Crowley SJ, Lee C, Tseng CY, Fogg LF, Eastman CI. Combinations of bright light, scheduled dark, sunglasses, and melatonin to facilitate circadian entrainment to night shift work. J Biol Rhythms. 2003;18: 513-523.

85. Jan JE, Hamilton D, Seward N, Fast DK, Freeman RD, Laudon M. Clinical trials of controlled-release melatonin in children with sleep-wake cycle disorders. J Pineal Res. 2000;29:34-39.

86. Wasdell MB, Jan JE, Bomben MM, Freeman RD, Rietveld WJ, Tai J, et al. A randomized, placebo-controlled trial of controlled release melatonin treatment of delayed sleep phase syndrome and impaired sleep maintenance in children with neurodevelopmental disabilities. J Pineal Res. 2008;44:57-64.

87. Potocki L, Glaze D, Tan DX, Park SS, Kashork CD, Shaffer LG, et al. Circadian rhythm abnormalities of melatonin in Smith-Magenis syndrome. J Med Genet. 2000;37:428-433.

88. De Leersnyder $H$. Inverted rhythm of melatonin secretion in Smith-Magenis syndrome: from symptoms to treatment. Trends Endocrinol Metab. 2006;17:291-298.

89. De Leersnyder H, Claustrat B, Munnich A, Verloes A. Circadian rhythm disorder in a rare disease: Smith-Magenis syndrome. Mol Cell Endocrinol. 2006;252:88-91.
90. Carpizo R, Martínez A, Mediavilla D, González M, Abad A, Sánchez-Barceló EJ. Smith-Magenis syndrome: a case report of improved sleep after treatment with $\beta 1$-adrenergic antagonists and melatonin. J Pediatr. 2006;149:409-411.

91. Jan JE, Espezel H, Appleton RE. The treatment of sleep disorders with melatonin. Dev Med Child Neurol. 1994;36:97-107.

92. McArthur AJ, Budden SS. Sleep dysfunction in Rett syndrome: a trial of exogenous melatonin treatment. Dev Med Child Neurol. 1998;40:186-192.

93. Ishizaki A, Sugama M, Takeuchi N. [Usefulness of melatonin for developmental sleep and emotional/behavior disorders-studies of melatonin trial on 50 patients with developmental disorders.] [in Japanese]. No To Hattatsu. 1999;31:428-437.

94. Andersen IM, Kaczmarska J, McGrew SG, Malow BA. Melatonin for insomnia in children with autism spectrum disorders. J Child Neurol. 2008;23:482-485.

95. Giannotti F, Cortesi F, Cerquiglini A, Bernabei P. An open-label study of controlled-release melatonin in treatment of sleep disorders in children with autism. J Autism Dev Disord. 2006;36:741-752.

96. Dolberg OT, Hirschmann S, Grunhaus L. Melatonin for the treatment of sleep disturbances in major depressive disorder. Am J Psychiatry. 1998;155:1119-1121.

97. Dalton EJ, Rotondi D, Levitan RD, Kennedy SH, Brown GM. Use of slow-release melatonin in treatment-resistant depression. J Psychiatry Neurosci. 2000;25:48-52.

98. Shilo L, Dagan Y, Smorjik Y, Weinberg U, Dolev S, Komptel B, et al. Effect of melatonin on sleep quality of COPD intensive care patients: a pilot study. Chronobiol Int. 2000;17:71-76.

99. Shamir E, Laudon M, Barak Y, Anis Y, Rotenberg V, Elizur A, et al. Melatonin improves sleep quality of patients with chronic schizophrenia. J Clin Psychiatry. 2000;61:373-377.

100. Shamir E, Rotenberg VS, Laudon M, Zisapel N, Elizur A. First-night effect of melatonin treatment in patients with chronic schizophrenia. J Clin Psychopharmacol. 2000;20:691-694.

101. Serfaty M, Kennell-Webb S, Warner J, Blizard R, Raven P. Double blind randomised placebo controlled trial of low dose melatonin for sleep disorders in dementia. Int $J$ Geriatr Psychiatry. 2002;17:1120-1127.

102. Borja NL, Daniel KL. Ramelteon for the treatment of insomnia. Clin Ther. 2006;28:1540-1555.

103. Neubauer DN. A review of ramelteon in the treatment of sleep disorders. Neuropsychiatr Dis Treat. 2008;4:69-79.

104. Roth T, Seiden D, Sainati S, Wang-Weigand S, Zhang J, Zee P. Effects of ramelteon on patient-reported sleep latency in older adults with chronic insomnia. Sleep Med. 2006;7:312-318.

105. Erman M, Seiden D, Zammit G, Sainati S, Zhang J. An efficacy, safety, and dose-response study of ramelteon in patients with chronic primary insomnia. Sleep Med. 2006;7:17-24.

106. Roth T, Seiden D, Wang-Weigand S, Zhang J. A 2-night, 3-period, crossover study on ramelteon's efficacy and safety in older adults with chronic insomnia. Curr Med Res Opin. 2007;23:1005-1014.

107. Zammit G, Erman M, Wang-Weigand S, Sainati S, Zhang J, Roth T. Evaluation of the efficacy and safety of ramelteon in subjects with chronic insomnia. J Clin Sleep Med. 2007;3:495-504.

108. Kryger M, Wang-Weigand S, Roth T. Safety of ramelteon in individuals with mild to moderate obstructive sleep apnea. Sleep Breath. 2007;11:159-164.

109. Otmani S, Demazières A, Staner C, Jacob N, Nir T, Zisapel N, et al. Effects of prolonged-release melatonin, zolpidem, and their combination on psychomotor functions, memory recall, and driving skills in healthy middle aged and elderly volunteers. Hum Psychopharmacol. 2008;23:693-705.

110. Garfinkel D, Zisapel N, Wainstein J, Laudon M. Facilitation of benzodiazepine discontinuation by melatonin: a new clinical approach. Arch Intern Med. 1999;159:2456-2460. 
111. Weishaupt JH, Bartels C, Pölking E, Dietrich J, Rohde G, Poeggeler B, et al. Reduced oxidative damage in ALS by high-dose enteral melatonin treatment. J Pineal Res. 2006;41:313-323.

112. Silman RE. Melatonin: a contraceptive for the nineties. Eur J Obstet Gynecol Reprod Biol. 1993;49:3-9.

113. García-Patterson A, Puig-Domingo M, Webb SM. Thirty years of human pineal research: do we know its clinical relevance? J Pineal Res. 1996;20:1-6.

114. Bubenik GA, Blask DE, Brown GM, Maestroni GJ, Pang SF, Reiter RJ, et al. Prospects of the clinical utilization of melatonin. Biol Signals Recept. 1998;7:195-219.

115. Silman R. Melatonin and the human gonadotrophin-releasing hormone pulse generator. J Endocrinol. 1991;128:7-11.

116. Waldhauser F, Boepple PA, Schemper M, Mansfield MJ, Crowley WF Jr. Serum melatonin in central precocious puberty is lower than in age-matched prepubertal children. J Clin Endocrinol Metab. 1991;73:793-796.

117. Walker AB, English J, Arendt J, MacFarlane IA. Hypogonadotrophic hypogonadism and primary amenorrhoea associated with increased melatonin secretion from a cystic pineal lesion. Clin Endocrinol (Oxf). 1996;45:353-356.

118. Luboshitzky R, Herer P, Shen-Orr Z. Urinary 6-sulfatoxymelatonin excretion in hyperandrogenic women: the effect of cyproterone acetate-ethinyl estradiol treatment. Exp Clin Endocrinol Diabetes. 2004;112:102-107.

119. Rohr UD, Herold J. Melatonin deficiencies in women. Maturitas. 2002;41 Suppl 1:S85-S104.

120. Luboshitzky R, Levi M, Shen-Orr Z, Blumenfeld Z, Herer P, Lavie P. Long-term melatonin administration does not alter pituitary-gonadal hormone secretion in normal men. Hum Reprod. 2000;15:60-65.

121. Luboshitzky R, Shen-Orr Z, Nave R, Lavi S, Lavie P. Melatonin administration alters semen quality in healthy men. $J$ Androl. 2002;23:572-578.

122. Palm L, Blennow G, Wetterberg L. Long-term melatonin treatment in blind children and young adults with circadian sleep-wake disturbances. Dev Med Child Neurol. 1997;39:319-325.
123. Jan JE, Freeman RD, Fast DK. Melatonin treatment of sleep-wake cycle disorders in children and adolescents. Dev Med Child Neurol. 1999;41:491-500.

124. Dodge NN, Wilson GA. Melatonin for treatment of sleep disorders in children with developmental disabilities. J Child Neurol. 2001;16:581-584.

125. Takeda Pharmaceuticals America, Inc. Rozerem ${ }^{\mathrm{TM}}$ (ramelteon) tablets. 05-1118;L-RAM-00010. 2005.

126. Willis GL. Parkinson's disease as a neuroendocrine disorder of circadian function: dopamine-melatonin imbalance and the visual system in the genesis and progression of the degenerative process. Rev Neurosci. 2008;19:245-316.

127. Willis GL. The role of ML-23 and other melatonin analogues in the treatment and management of Parkinson's disease. Drug News Perspect. 2005;18:437-444.

128. Osadchuk AM, Osadchuk MA, Kvetnoĭ IM. [Irritated bowel syndrome: clinico-morphological types.] [Article in Russian] Klin Med (Mosk). 2007;85:46-50.

129. Hardeland R, Pandi-Perumal SR, Cardinali DP. Molecules in focus - Melatonin. Int J Biochem Cell Biol. 2006;38:313-316.

130. Fava M, Asnis G, Shrivastava R, Lydiard RB, Bastani B, Sheehan D, et al. Improved insomnia symptoms and daily functioning in patients with comorbid major depressive disorder and insomnia following zolpidem extended-release $12.5 \mathrm{mg}$ and escitalopram co-treatment. Sleep. 2008;31:A324.

131. Kryger M, Roth T, Wang-Weigand S, Zhang J. The effects of ramelteon on respiration during sleep in subjects with moderate to severe chronic obstructive pulmonary disease. Sleep Breath. 2009;13:79-84.

132. Roth T. Hypnotic use for insomnia management in chronic obstructive pulmonary disease. Sleep Med. 2009;10:19-25.

133. Nunes DM, Mota RM, Machado MO, Pereira ED, de Bruin VM, de Bruin PF. Effect of melatonin administration on subjective sleep quality in chronic obstructive pulmonary disease. Braz J Med Biol Res. 2008;41:926-931.
Neuropsychiatric Disease and Treatment

\section{Publish your work in this journal}

Neuropsychiatric Disease and Treatment is an international, peerreviewed journal of clinical therapeutics and pharmacology focusing on concise rapid reporting of clinical or pre-clinical studies on a range of neuropsychiatric and neurological disorders. This journal is indexed on PubMed Central, the 'PsycINFO' database and CAS, and is the official

\section{Dovepress}

journal of The International Neuropsychiatric Association (INA). The manuscript management system is completely online and includes a very quick and fair peer-review system, which is all easy to use. Visit http://www.dovepress.com/testimonials.php to read real quotes from published authors. 